\title{
Seasonal Characteristics of Tourism Flow Network Structure in Guangdong Residents from the Perspective of Social Network
}

\author{
Zhongyu Wang, Yi Liu \\ School of Management, Jinan University, Guangzhou, China \\ Email: 18712706553@163.com
}

How to cite this paper: Wang, Z.Y. and Liu, Y. (2020) Seasonal Characteristics of Tourism Flow Network Structure in Guangdong Residents from the Perspective of Social Network. Open Journal of Business and Management, 8, 683-695. https://doi.org/10.4236/ojbm.2020.82041

Received: February 26, 2020

Accepted: March 14, 2020

Published: March 17, 2020

Copyright $\odot 2020$ by author(s) and Scientific Research Publishing Inc. This work is licensed under the Creative Commons Attribution International License (CC BY 4.0).

http://creativecommons.org/licenses/by/4.0/

\begin{abstract}
Based on the Baidu index of $4 \mathrm{~A}$ and $5 \mathrm{~A}$ scenic spots in Guangdong province, this research obtained the data of residents' attention to the network of scenic spots in Guangdong province, and used the social network analysis method to explore the seasonal characteristics of residents' tourism flow network structure in Guangdong province. The results show that: 1) There are seasonal differences in the output and input capacity of tourism flow in node cities within the tourism flow network of residents in Guangdong province, and the control effect of core node cities on other cities is most prominent in winter. 2) The "core-edge" structure of the tourism flow network of residents in Guangdong province has obvious seasonal characteristics. From spring to winter, the interaction between node cities in the core region is gradually weakened and then strengthened. 3) In the tourism flow network of residents in Guangdong province, the roles of tourist destinations and tourist sources of each section will change in different seasons, and there are seasonal differences in the flow directions and flows of tourist sources among sections.
\end{abstract}

\section{Keywords}

Tourism Flow, Network Structure, Social Network Analysis

\section{Introduction}

In recent years, China's tourism has developed strongly. In 2018, the number of domestic tourists was 5.539 billion, and the total tourism revenue for the whole year was 5.97 trillion yuan, a year-on-year increase of $10.5 \%$. Among them, there were 11,924 A-level scenic spots nationwide at the end of 2018, the total number of people received in the whole year was 6024 million, and tourism in-come 
reached 470.754 billion yuan (Statistical bulletin of the ministry of culture and tourism, PRC on cultural and tourism development 2018). Among them, the city, as a core component of the development of tourism, has become an important support for the development of modern tourism. With the rapid development of modern tourism, the links between urban tourism flows are getting closer and closer, their interactions are getting more and more frequently, the spatial network structure of tourism flow at different scales begins to take shape. The current study of tourist flow space network structure gradually rises in recent years; scholars have gradually started to research from the perspective of macro-regional tourism flow network space structure. There are few studies on the structural characteristics of tourism flows within the region, and the structural characteristics of tourism flow network from the microscopic perspective are not clear at present. Meanwhile, there is also the problem of insufficient sample representation at the data acquisition level. On the basis of existing research, this paper selected Guangdong province as the case site, collected the data of attention paid by urban residents of Guangdong province to the network of tourism scenic spots in the province in 2018, and systematically analyzed the seasonal characteristics and specific differences of the network structure of tourism flow in the province of residents in the scenic spots of Guangdong province with the help of social network analysis method.

\section{Literature Review}

For a long time, the research on tourism flow has been the focus of domestic tourism scholars. In this field, domestic tourism scholars have achieved fruitful research results. The main research contents include the basic theory of tourism flow [1] [2] [3], the mechanism of tourism flow [4] [5] [6], the flow of tourism flow [7] [8], the spatial pattern of tourism flow [9] [10] [11], the effect of tourism flow [12] [13], the evolution mechanism of tourism flow [14] [15], and so on. It has become a new research hotspot. Researchers focus on the use of social network analysis methods. Most of the research objects are inbound tourism flows. They have carried out research from national, regional and provincial scales, focusing on the specific characteristics of the spatial network structure of tourism flows [16] [17], network structure optimization [18], network structure evolution [19], and specific factors affecting network structure [20]. Overall, the research on the characteristics of the spatial network structure of tourism streams is relatively weak. The research data are mainly obtained from questionnaire survey data [16], travel website travel journals [21] [22], and tourist routes [23]. The data source is single and the number of samples is limited and insufficiently representative, it is difficult to accurately measure the spatial network structure characteristics of tourist flows.

With the rapid development of the Internet, tourists have gradually started to use the Internet to search for tourist destination-related information. The size of the search number can indicate the tourist's online attention to the destination, 
and it can also reflect the tourist's demand to the tourist destination. At the same time, some studies have pointed out that the network attention of tourist destinations is closely related to the number of tourists, and the characteristics of tourism flow can be reflected by the network attention of tourist destinations [24] [25]. Some scholars have used Baidu index to study the structure of tourism flow network [26] [27] [28]. This article selects Guangdong Province as a case and relies on the Baidu index search platform to collect data on the attention of 21 city residents in Guangdong Province to the 4A and 5A tourist attractions in the province in 2018. Using social network analysis methods to systematically analyze Guangdong Province Seasonal characteristics of the tourism flow network structure of the residents in the tourist attractions in the province and their specific differences, and a deep understanding of the seasonal characteristics of the tourism flow structure of the residents in Guangdong from the scenic level, which has certain reference for the future cooperation and development of regional tourism markets in Guangdong Province and regional tourism marketing significance.

\section{Study Design}

\subsection{Data Source and Processing}

This study uses the Baidu index search platform (Baidu is the Internet search engine with the highest market share in China. The Baidu index used in this paper is derived from Baidu index platform, in which specific keywords are input and Baidu index platform will output the Baidu index value of that keyword, including the change of time trend, combined with the Guangdong 4A and 5A tourist attractions list, to collect the monthly average network attention data of residents of a city in Guangdong Province to other cities' $4 \mathrm{~A}$ and 5A tourist attractions each month in 2018, and the monthly average network attention was multiplied by the number of days in each month. The monthly network attention of residents in a certain city to $4 \mathrm{~A}$ and $5 \mathrm{~A}$ tourist attractions in other cities can be obtained, then the monthly Internet attention is added up, finally the Internet attention of each area in each season is obtained.

\subsection{Research Methods}

This paper mainly uses the social network analysis method, the network refers to the stable relationship formed among many elements. Social network refers to the structure of relationships among groups, organizations and individuals in the society due to resource dependence. The social network analysis method is a technique used to analyze the structure, nature and attributes of the relationships among network participants [29]. Social network analysis is a set of norms and methods to analyze the structure and attributes of social relations. Its research object is the relations and attributes formed by the interdependence and mutual influence among actors, rather than the attribute characteristics of actors themselves. The interaction between the participants is the basis of social net- 
work analysis, and the interaction and resource dependence between the participants produce collective behavior. In the concrete operation, usually uses the UCINET6.0 software to carry out the analysis. This research mainly uses the social network analysis method to import the residents attention to the $4 \mathrm{~A}$ and $5 \mathrm{~A}$ tourist attractions in Guangdong Province into UCINET 6.0 software, analyze the characteristics of social network structure nodes, and use the Network section to perform core-edge analysis and block model analysis. The core-edge analysis mainly divides the internal nodes of the network based on the core-edge model, and then reveals the core-edge structure of the social network. Block model analysis is to use the CONCOR program to slice the internal nodes of the network, and to better explain the social network structure based on the interaction between the section.

\section{Seasonal Differences of Resident Tourism Flow Network in Guangdong Province}

This paper takes 21 cities in Guangdong Province as nodes, and builds an overall matrix of residents "tourism flow network in Guangdong Province based on the collected residents" network attention data.

\subsection{Network Structure Node Features}

The network attention data in the original matrix can reflect the tourist flow output and introduction of each node city in the tourist travel network in Guangdong Province. In contrast, the spring and summer seasons are the peak tourist seasons in Guangdong Province, and the node cities within the network have the largest output and input of tourism flows in the spring and summer seasons. In terms of cities, there are also differences in the output flow and the amount of tourism flow in different node cities in different seasons. Among them, Guangzhou and Shenzhen have the highest output of tourist flows throughout the year (the Internet attention is more than 1,000,000), as the main tourist source of other cities in Guangdong Province. At the same time, Guangzhou is basically unaffected by the seasons. The number of tourist flows introduced throughout the year is the highest (at least 1,000,000 online attention), and the tourist flow input ability is strong. In addition, other cities such as Foshan, Dongguan, and Huizhou also have prominent output flow and input capabilities, and are less affected by seasonal effects. They are also the main tourist destinations and tourist source areas of other cities in Guangdong Province. The output and input capacity of tourist flows in other cities are weak and greatly affected by seasonality. In the future, it is still necessary to strengthen links with other node cities.

This research further uses UCINET 6.0 software to measure the intermediate centrality of the residents' tourist flow network nodes in Guangdong Province, and to clarify the degree of control of one node city over other node cities in the network. The measurement results are shown in Table 1. It can be seen that 
Table 1. The betweenness centrality of node.

\begin{tabular}{|c|c|c|c|c|}
\hline City & Spring & Summer & Autumn & Winter \\
\hline Guangzhou & 5.014 & 3.428 & 6.667 & 7.863 \\
\hline Shenzhen & 3.868 & 3.428 & 5.300 & 5.565 \\
\hline Zhuhai & 2.470 & 3.211 & 1.411 & 1.980 \\
\hline Foshan & 5.014 & 2.383 & 4.342 & 6.030 \\
\hline Shantou & 0.459 & 0.563 & 0.491 & 0.741 \\
\hline Shaoguan & 4.215 & 2.383 & 4.210 & 5.384 \\
\hline Heyuan & 0.000 & 0.033 & 0.000 & 0.000 \\
\hline Meizhou & 0.096 & 0.033 & 0.187 & 0.053 \\
\hline Huizhou & 5.014 & 3.428 & 5.000 & 4.264 \\
\hline Shanwei & 0.508 & 1.741 & 0.187 & 0.436 \\
\hline Dongguan & 3.868 & 2.659 & 3.151 & 5.565 \\
\hline Jiangmen & 0.686 & 0.077 & 0.000 & 1.184 \\
\hline Zhanjiang & 0.886 & 0.923 & 2.763 & 0.627 \\
\hline Maoming & 0.547 & 0.288 & 1.066 & 0.363 \\
\hline Zhaoqing & 0.685 & 0.705 & 0.633 & 0.743 \\
\hline Qingyuan & 0.048 & 0.077 & 0.439 & 0.301 \\
\hline Chaozhou & 0.621 & 2.842 & 0.737 & 0.412 \\
\hline Jieyang & 0.153 & 0.138 & 0.240 & 0.105 \\
\hline Yunfu & 0.334 & 0.081 & 0.491 & 0.384 \\
\hline Yangjiang & 0.197 & 0.000 & 0.053 & 0.053 \\
\hline
\end{tabular}

Guangzhou, Shenzhen, Foshan, Shaoguan, Huizhou, and Dongguan have higher centrality than other cities, indicating that these cities have a controlling role in other node cities in the network and are at the core of the network. At the same time, the number of core node cities is more in spring, autumn, and winter than in summer. Guangzhou has the highest degree of centrality in different seasons, and has the strongest control over other node cities. In addition, the central degree of major core cities in winter is significantly greater than in other seasons, indicating that the control of core cities over other cities is more obvious in winter.

\subsection{Core-Edge Analysis}

UCINET 6.0 software was used to perform core-edge analysis on the tourism flow network of residents in Guangdong in different seasons.

Based on the analysis results shown in Table 2, the cities in Guangdong province where the tourist flow network is located in the core regions throughout the year which include Guangzhou, Shenzhen, Zhuhai, Foshan, Shaoguan, Huizhou, and Dongguan. These node cities are not affected by seasonality and they are the main cities in Guangdong Tourist destination and tourist source. At the same time, the overall number of node cities in the core region show a fluctuating 
Table 2. Core-edge analysis results.

\begin{tabular}{|c|c|c|c|c|}
\hline Season & $\begin{array}{l}\text { The number } \\
\text { of core cities }\end{array}$ & $\begin{array}{l}\text { The number } \\
\text { of edge cities }\end{array}$ & $\begin{array}{l}\text { The density } \\
\text { of core area }\end{array}$ & $\begin{array}{l}\text { The density } \\
\text { of edge areas }\end{array}$ \\
\hline Spring & $\begin{array}{l}\text { Guangzhou } \\
\text { Shenzhen } \\
\text { Zhuhai } \\
\text { Foshan } \\
\text { Shaoguan } \\
\text { Huizhou } \\
\text { Dongguan }\end{array}$ & $\begin{array}{c}\text { Shantou } \\
\text { Heyuan } \\
\text { Meizhou } \\
\text { Shanwei } \\
\text { Zhongshan } \\
\text { Jiangmen } \\
\text { Zhanjiang } \\
\text { Maoming } \\
\text { Zhaoqing } \\
\text { Qingyuan } \\
\text { Chaozhou } \\
\text { Jieyang } \\
\text { Yunfu } \\
\text { Yangjiang }\end{array}$ & 0.976 & 0.181 \\
\hline Summer & $\begin{array}{c}\text { Guangzhou } \\
\text { Shenzhen } \\
\text { Zhuhai } \\
\text { Foshan } \\
\text { Shantou } \\
\text { Shaoguan } \\
\text { Huizhou } \\
\text { Shanwei } \\
\text { Dongguan } \\
\text { Zhongshan } \\
\text { Jiangmen } \\
\text { Maoming }\end{array}$ & $\begin{array}{c}\text { Heyuan } \\
\text { Meizhou } \\
\text { Zhanjiang } \\
\text { Zhaoqing } \\
\text { Chaozhou } \\
\text { Jieyang } \\
\text { Yunfu } \\
\text { Yangjiang }\end{array}$ & 0.846 & 0.036 \\
\hline Autumn & $\begin{array}{c}\text { Guangzhou } \\
\text { Shenzhen } \\
\text { Zhuhai } \\
\text { Foshan } \\
\text { Shantou } \\
\text { Shaoguan } \\
\text { Huizhou } \\
\text { Dongguan } \\
\text { Zhongshan } \\
\text { Jiangmen } \\
\text { Zhanjaing }\end{array}$ & $\begin{array}{c}\text { Heyuan } \\
\text { Meizhou } \\
\text { Shanwei } \\
\text { Maoming } \\
\text { Zhaoqing } \\
\text { Qingyuan } \\
\text { Chaozhou } \\
\text { Jieyang } \\
\text { Yunfu } \\
\text { Yangjiang }\end{array}$ & 0.845 & 0.111 \\
\hline Winter & $\begin{array}{c}\text { Guangzhou } \\
\text { Shenzhen } \\
\text { Zhuhai } \\
\text { Foshan } \\
\text { Shantou } \\
\text { Shaoguan } \\
\text { Huizhou } \\
\text { Dongguan } \\
\text { Zhongshan } \\
\text { Jiangmen }\end{array}$ & $\begin{array}{c}\text { Heyuan } \\
\text { Meizhou } \\
\text { Shanwei } \\
\text { Zhanjiang } \\
\text { Maoming } \\
\text { Zhaoqing } \\
\text { Qingyuan } \\
\text { Chaozhou } \\
\text { Jieyang } \\
\text { Yunfu } \\
\text { Yangjiang }\end{array}$ & 0.867 & 0.100 \\
\hline
\end{tabular}


trend, and the number of cities in the three seasons of summer, autumn, and winter was significantly more than that in spring. In addition, in terms of cities, Maoming and Shanwei are only in the core area in summer, indicating that these cities have more obvious advantages in tourism development in summer. However, Zhanjiang is only in the core area in autumn, which indicates that its tourism development is more prominent in autumn throughout the year. In addition, from the comparison of regional density, the density of the core area is significantly higher than the density of the edge area, which indicates that there is a closer tourist flow connection between the node cities within the core area. Among them, in the core areas, the core area density of the tourist stream in the spring and winter seasons is significantly higher than in the other two seasons, which indicates that the node cities in the core area of residents' tourist stream in Guangdong Province are more closely connected and interact more frequently in the spring and winter seasons. At the same time, this part also shows obvious seasonal characteristics, that is, from spring to winter, the interactions between the nodes in the core regions show the characteristics of "first descending, then rising".

\subsection{Block Model Analysis}

In order to further understand the seasonal differences in the Internal section connection connections of tourism flow networks, the CONCOR program in UCINET 6.0 software was used to segment the residents' tourism flow network in Guangdong Province and turn it into an inter-sector network. The analysis results are shown in Figure 1.

The location type of each section is clear, and the seasonal differences are obvious. Among them, from spring to winter, the first section is the main tourist destination of the two, three, and four sections, and its internal cities are also tourist sources and destinations. At the same time, the tourist source area of the first section is mainly concentrated in the third and fourth sections in spring, summer and autumn, and expanded to the second section in winter. While the

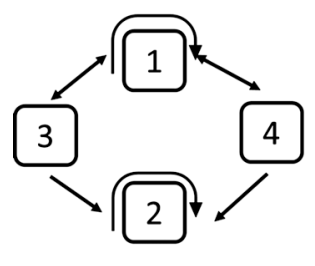

Spring

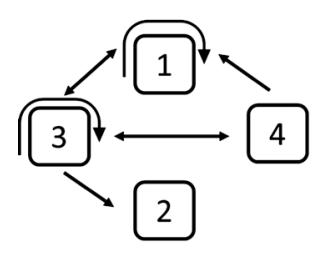

Autumn
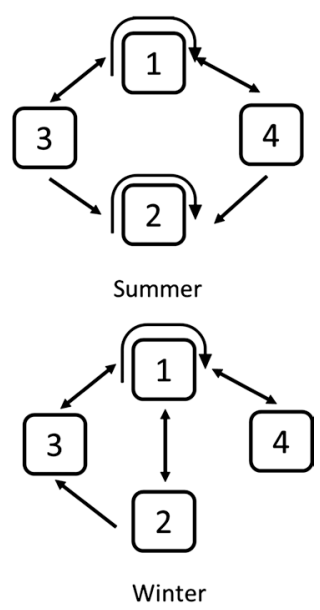

Figure 1. Guangdong province residents travel network section mutual relations. 
second section is the main tourist destination of the third and fourth section in the spring and summer seasons, there are also closer tourism flow links between its inner cities. In addition, the second section has less contact with other sections in the autumn and winter seasons, and is only used as a tourist source for the third section. The third section has a stable tourist flow output and input with the first section throughout the year, but the connection with the second section is changed from the tourist flow output in the spring, summer, and autumn seasons to the winter tourist flow input. The location type of the fourth section changes significantly with the seasons. It maintains a stable tourism flow with the first section throughout the year, and the two sections are each other's tourist destination and tourist source. The fourth section is the main tourist source of the second section in the spring and summer seasons, and there is also an interactive connection with the tourist flow in the third section in the fall. In addition, in combination with the position of each season, the third section in autumn and the first section in winter maintain tourism flow with other sections. Among them, the third section in autumn, the first section, and the fourth section are each other's tourist destination and tourist source At the same time, it also serves as the main tourist source of the second section; in the winter, the first section and the other three sections are each other's tourist destination and tourist source. Referring to the section cutting results shown in Table 3, both types of sections include Shenzhen, Foshan, and Dongguan. It shows that these cities play an important role in the tourism flow network of residents in Guangdong Province. As the most important tourist destination in Guangdong Province, the tourist source covers other cities in the province. Finally, the tourism flow between the cities in each sector is obvious in the four seasons of the year. It is mainly concentrated in the four cities of Guangzhou, Shenzhen, Foshan, and Dongguan. Among them, Shenzhen and Foshan are not affected by seasonal factors, and they maintain stable tourist flows with cities within the section throughout the year.

The results of this research show that: 1) The capacity of tourism flow output and input is outstanding in spring and summer in the inner node cities of Guangdong residents' tourism flow network. The number of core node cities in spring, autumn and winter is more than that in summer. 2) The "Core-edge" structure of residents' tourism flow network in Guangdong province has obvious seasonal characteristics. The number of nodal cities in the core region in summer, autumn and winter is significantly higher than that in spring. In spring and winter, nodal cities in the core region also show a closer connection of tourism flow. From spring to winter, the interaction between node cities in the core region is characterized by "falling first, rising later". 3) In the tourism flow network of residents in Guangdong province, the characteristics of each section and the connections between sections have seasonal characteristics. The position types of the four sections in different sea-sons will all change, and there is a seasonal difference between the output and the input of tourism flow between sections. 
Table 3. Section cutting results.

\begin{tabular}{|c|c|c|}
\hline Season & Section type & Cities \\
\hline \multirow[t]{21}{*}{ Spring } & The first section & Guangzhou \\
\hline & & Shenzhen \\
\hline & & Foshan \\
\hline & & Dongguan \\
\hline & The second section & Zhuhai \\
\hline & & Shaoguan \\
\hline & & Huizhou \\
\hline & & Qingyuan \\
\hline & The third sector & Shantou \\
\hline & & Heyuan \\
\hline & & Meizhou \\
\hline & & Shanwei \\
\hline & & Chaozhou \\
\hline & & Jieyang \\
\hline & The fourth section & Maoming \\
\hline & & Zhaoqing \\
\hline & & Zhongshan \\
\hline & & Jiangmen \\
\hline & & Zhanjiang \\
\hline & & Yunfu \\
\hline & & Yangjiang \\
\hline \multirow[t]{21}{*}{ Summer } & The first section & Guangzhou \\
\hline & & Shenzhen \\
\hline & & Foshan \\
\hline & The second section & Zhuhai \\
\hline & & Maoming \\
\hline & & Shaoguan \\
\hline & & Qingyuan \\
\hline & & Shanwei \\
\hline & & Huizhou \\
\hline & The third sector & Jiangmen \\
\hline & & Dongguan \\
\hline & & Zhongshan \\
\hline & & Shantou \\
\hline & & Zhanjiang \\
\hline & & Yangjiang \\
\hline & & Zhaoqing \\
\hline & & Yunfu \\
\hline & The fourth section & Meizhou \\
\hline & & Heyuan \\
\hline & & Chaozhou \\
\hline & & Jieyang \\
\hline \multirow[t]{6}{*}{ Autumn } & The first section & Guangzhou \\
\hline & & Qingyuan \\
\hline & & Zhuhai \\
\hline & & Huizhou \\
\hline & & Maoming \\
\hline & & Shaoguan \\
\hline
\end{tabular}




\section{Continued}

\begin{tabular}{|c|c|c|}
\hline & The second section & Chaozhou \\
\hline & & Meizhou \\
\hline & & Yunfu \\
\hline & & Shanwei \\
\hline & The third sector & Shenzhen \\
\hline & & Foshan \\
\hline & & Dongguan \\
\hline & The fourth section & Zhongshan \\
\hline & & Zhanjiang \\
\hline & & Zhaoqing \\
\hline & & Heyuan \\
\hline & & Jiangmen \\
\hline & & Jieyang \\
\hline & & Shantou \\
\hline & & Yangjiang \\
\hline \multirow[t]{21}{*}{ Winter } & The first section & Guangzhou \\
\hline & & Shenzhen \\
\hline & & Foshan \\
\hline & & Dongguan \\
\hline & The second section & Jiangmen \\
\hline & & Shantou \\
\hline & & Zhongshan \\
\hline & & Zhanjiang \\
\hline & & Jieyang \\
\hline & & Yangjiang \\
\hline & & Zhaoqing \\
\hline & The third sector & Zhuhai \\
\hline & & Maoming \\
\hline & & Yunfu \\
\hline & & Huizhou \\
\hline & & Qingyuan \\
\hline & & Shaoguan \\
\hline & The fourth section & Chaozhou \\
\hline & & Meizhou \\
\hline & & Shanwei \\
\hline & & Heyuan \\
\hline
\end{tabular}

\section{Research Conclusions}

- There are differences in seasonal characteristics of tourist flow connections between node cities. The nodes in the network have the largest output and input of tourism flow in the spring and summer. Guangzhou, Shenzhen, Foshan, Dongguan and other major node cities are most closely linked to other cities in the network, and are less affected by seasonality. They also show strong control over other cities and are at the core of the network. In addition, the number of core node cities is more in spring, autumn, and winter than in summer. In winter, the control effect of core node cities in other cities is more obvious. 
- The seasonal characteristics of the "Core-Edge" structure of the tourism flow network of residents in Guangdong Province are obvious. Guangzhou, Shenzhen, Zhuhai, Foshan, Shaoguan, Huizhou, Dongguan and other cities are in the core area of the network throughout the year and nodes The number of cities in summer, autumn, and winter was significantly more than in spring. In addition, there is a closer tourist flow connection between the inner node cities in the core area than in the peripheral areas. The node cities in the core regions in spring and winter also show closer tourism flow links. At the same time, from spring to winter, the interactions between the nodes in the core regions have formed a characteristic of "first descending and then rising".

- There is also certain seasonality in the characteristics of each section and the relationship between the sections in the tourism flow network of residents in Guangdong Province. The four section types will change in different seasons, and there will be seasonal differences in the output and input of tourism flows between the sections. In addition, the third section in autumn and the first section in winter maintain stable tourism flow with other sections throughout the year. Both types of sections include Shenzhen, Foshan, and Dongguan. At the same time, the internal cities with tourism flow links in each section are mainly concentrated in Guangzhou, Shenzhen, Foshan, and Dongguan. Among them, Shenzhen and Foshan have close tourist flow links with the cities within the section throughout the year.

\section{Acknowledgements}

This study was supported by the National Social Science Foundation of China (NSSFC) [grant number: 17BJY230].

\section{Conflicts of Interest}

The authors declare no conflicts of interest regarding the publication of this paper.

\section{References}

[1] Tang, S.T. and Guo, L.X. (1998) Study on Tourism Flow System. Tourism Tribune, 13, 38-41.

[2] Wu, J.F. and Bao, H.S. (2005) Research on the Distance of the Tourist Flow. Human Geography, 20, 62-65.

[3] Zhong, S.E., Zhang, J., Han, G.S. Wang, L. and Zhang, H.L. (2010) Spatial Patterns of Tourist Flow: Problems and Prospects. Human Geography, No. 2, 31-36.

[4] Zheng, P., Ma, Y.F., Wang, J.J., Li, J.Y. and Yang, M. (2010) A Study of the Influencing Factors of the Inbound Tourists from the USA Based on "Push-Pull" Theory. Human Geography, No. 5, 112-117.

[5] Yang, X.Z., Gu, C.L. and Wang, Q. (2011) Study on the Driving Force of Tourist Flows. Geographical Research, 30, 23-36.

[6] Yao, Y.X., Guan, W.H. and Li, Z.J. (2016) An Analysis of the Temporal-Spatial 
Evolution of Inbound Tourist Flow of Jiangsu Province and Its Influencing Factors. Tourism Science, 30, 52-62.

[7] Lu, X.B., Chen, X.Y. and Ma, B.B. (2015) Tourism Flow Scales and Potentials among Northeast Asian Countries. Journal of Arid Land Resources and Environment, 29, 208-213.

[8] Zheng, T.X., Wu, R. and Luo, H.Y. (2015) A Review of Automatic Generalization of Geomorphology and Water System. Geography and Information Science, 31, 90-96.

[9] Li, Z.F. and Xia, L. (2013) Spatial and Temporal Characteristics of the Tourist Flow in Special Time Period: A Case Study of Golden Week around National Day. Tourism Tribune, 28, 37-46.

[10] Li, C.X., Ma, Y.F. and Zhang, Y. (2012) Dynamic Evolution Mode of Regional Dominance Indexes of Chinese Tourism Flows During 1993 to 2008: An Empirical Research Based on Modified Entropy Technology. Geographical Research, 31, 257-268.

[11] Qin, J., Li, L.P., Tang, M.D., Sun, Y. and Song, X.R. (2018) Exploring the Spatial Characteristics of Beijing Inbound Tourist Flow Based on Geotagged Photos. Acta Geographica Sinica, 73, 1557-1570.

[12] Wang, Z.F. and Li, X.J. (2011) The Spatial Temporal Differences Dynamic Analysis of the Coupling Coordination about the Inbound Tourists Flows and Regional Economic-Based on the 31 Provinces Regional Panel Data from 1993-2011. Economic Geography, 31, 2122-2127.

[13] Liu, J.S., Ma, Y.F. and Wu, B. (2012) Network Structure of Multicity Inbound Tourists to China. Progress in Geography, 31, 518-526.

[14] Li, C.X., Ma, Y.F. and Zhang, Y. (2012) The Spatial Field Effect and Regional Structure of Concentration and Diffusion the Spatial Field Effect and Regional Structure of Concentration and Diffusion of Inbound Tourism Flows on Spatial and Temporal Scale of Inbound Tourism Flows on Spatial and Temporal Scale: Case of Typical District of the Eastern Part of the Silk Road. Scientia Geographica Sinica, 32, 176-185.

[15] Zhang, C.H., Ma, Y.F. and Bai, K. (2016) The System Coupling between Tourist Flow and Destination: An Empirical Analysis of Inbound Tourism in Six Major Cities. Resources Science, 38, 1013-1027.

[16] Wang, Y.M., Ma, Y.F. and Wang, M.X. (2012) Network Structure of Multicity Inbound Tourists to China. Progress in Geography, 31, 518-526.

[17] Liu, D.J. (2018) Spatial Pattern and Development Model of Tourist Flow in Urban Ag glomeration in the Middle Reaches of the Yangtze River. Economic Geography, 38, 217-223.

[18] Chen, X.Q. and Huang, F.C. (2006) Game Theory Application on Free Riding in Non-Equilibrium Spatial Competition of Tourism Destinations. Geography and Geo-Information Science, 22, 70-74.

[19] Yang, X.Z. and Wu, J. (2015) A Diachronic Comparison of the Characteristics of the Structure of Tourism Flow Network in Nanjing. Tourism Science, 29, 35-46.

[20] Xu, M., Huang, Z.F., Cao, F.D. and Zhu, H.Z. (2018) The Network Structure Features and Influence Factors of Tourism Flows Based on Online Data Analysis-Taking the Yangtze River Delta Region as an Example. Economic Geography, No. 6, 194-202.

[21] Wang, J., Hu, J., Jia, Y.Y., Liu, D.J., Xu, X.T. and Zhu, L. (2016) City Tourism Flow Network Structure and Transportation Mode-Taking Wuhan DIY Tourists for 
Example. Economic Geography, 36, 176-184.

[22] Wei, H.Y., Dai, Z.F., Xu, X. and Feng, X.G. (2018) The Impact of Shanghai Disneyland on Shanghai's Tourist Flow Network: From the Perspective of Tourists' Digital Footprints on the Lvmama Website. Tourism Tribune, No. 4, 33-45.

[23] Ruan, W.Q., Zhang, S.N. and Zheng, X.M. (2018) A Study on the Network Structure of Chinese Tourists' Traveling to Thailand and Its Formation Mechanism. World Regional Studies, No. 4, 34-44.

[24] Wang, S., Zeng, K.F., Tong, J. and Liu, C. (2013) A Correlative Analysis of the Relationship between Tourists and Tourist Network Attention for Scenic Spots in Special Session. Economic Geography, 33, 182-186.

[25] Li, S., Qiu, X.R. and Chen, L. (2008) Cyberspace Attention of Tourist Attractions Based on Baidu Index: Temporal Distribution and Precursor Effect. Geography and Geo-Information Science, 24, 102-107.

[26] Sun, Y., Zhang, H.L., Liu, P.X. and Zhang, J. (2017) Forecast of Tourism Flow Volume of Tourist Attraction Based on Degree of Tourist Attention of Travel Network: A Case Study of Baidu Index of Different Clients. Human Geography, No. 3, 158-166.

[27] Ding, X., Wang, J.Q. and Li, Y.Q. (2018) Study on Characteristics and Influencing Factors of Network Attention Degree of Tourist Destination Based on Baidu Index: A Case of Xiamen. Resource Development Market, 34, 709-714.

[28] Ma, L. and Xiao, Y. (2018) The Structure Characteristics of Domestic Tourist Flow Network in Typical Urban Dweller. Economic Geography, 38, 198-206.

[29] Fei, Z.L. and Wang, J.A. (2010) Social Network Analysis Method and Perspective of Management Research. Science and Technology Management Research, No. 24, 217-219. 